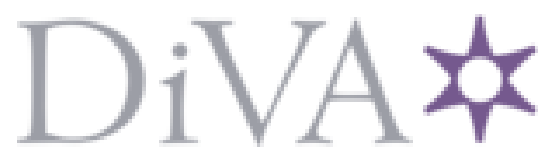

http://www.diva-portal.org

This is the published version of a paper published in International Journal of Refractory Metals and Hard Materials.

Citation for the original published paper (version of record):

Sheikh, S. (2014)

Fracture toughness of cemented carbides: Testing method andmicrostructural effects.

International Journal of Refractory Metals and Hard Materials, (8)

http://dx.doi.org/10.1016/j.jjrmhm.2014.08.018

Access to the published version may require subscription.

N.B. When citing this work, cite the original published paper.

Permanent link to this version:

http://urn.kb.se/resolve?urn=urn:nbn:se:kth:diva- 160524 


\title{
Fracture toughness of cemented carbides: Testing method and microstructural effects
}

\author{
Saad Sheikh ${ }^{\mathrm{a}, \mathrm{b}, *}$, Rachid M'Saoubi ${ }^{\mathrm{a}}$, Petr Flasar ${ }^{\mathrm{c}}$, Martin Schwind ${ }^{\mathrm{a}}$, Tomas Persson ${ }^{\mathrm{a}}$, Jing Yang ${ }^{\mathrm{d}}$, Luis Llanes ${ }^{\mathrm{d}}$ \\ a Seco Tools AB, RED Material and Technology Development, Fagersta 73782, Sweden \\ b Surface and Microstructure Engineering, Dept. of Materials and Manufacturing Technology, Chalmers University of Technology, 41296, Sweden \\ c Pramet Tools, s.r.o., Czech Republic \\ d CIEFMA- Universitat Politècnica de Catalunya, Dept. of Materials Science and Metallurgical Engineering, Avda. Diagonal 647, Barcelona 08028, Spain
}

\section{A R T I C L E I N F O}

\section{Article history:}

Received 9 June 2014

Received in revised form 21 August 2014

Accepted 23 August 2014

Available online $\mathrm{xxxx}$

\section{Keywords:}

Fracture toughness

Microstructural characterization

\begin{abstract}
A B S T R A C T
Fracture toughness is one the most important parameters for design applications and performance assessment of WC-Co cemented carbides (hardmetals). Different from hardness, fracture toughness is commonly a property more difficult to evaluate, particularly in brittle materials. A large number of different testing methods have been introduced to evaluate toughness of hardmetals, but in general all of them have either theoretically debatable issues or important experimental difficulties. In this study, three different fracture toughness testing methodologies are investigated: three-point bending on Chevron notched specimen ("reference" baseline), Palmqvist indentation test, and Hertzian indentation method. The work is conducted in several cemented carbide grades with different microstructures, in terms of both WC grain size and Co binder content. It is found that Chevronnotched three-point bending test yields suitable fracture toughness values for a wide range of cemented carbide grades with varying hardness. Concerning indentation methods, the Hertzian one may be particularly recommended, as compared to Palmqvist method, as far as hardness (HV30) drops below 1300. On the other hand, if HV30 is higher than 1300 Palmqvist indentation procedure yields reliable fracture toughness measurements. Experimental findings are finally analyzed and discussed on the basis of two theoretical models proposed in the literature.
\end{abstract}

(c) 2014 Elsevier Ltd. All rights reserved.

\section{Introduction}

WC-Co cemented carbides, also referred to as hardmetals, exhibit an excellent combination of mechanical properties. This is the main reason for its successful implementation as tool materials in a wide range of applications: metal cutting, mining, machining and metal forming, among others [1]. Among these properties, fracture toughness is one of the most important parameters for design applications and performance assessment of cemented carbides. Keeping fair toughness and maximizing hardness are primary concerns of hardmetal industry. However, different from hardness, fracture toughness is commonly a property more difficult to evaluate, particularly in brittle materials. In this regard, a large number of different testing methods have been introduced to evaluate toughness of hardmetals: Palmqvist indentation method, impact strength test on plane or notched bars, fracture mechanics protocols using either notched (Chevron or V-notch) or precracked specimens, etc. (e.g. Refs. [2-7]). In general, all of them have either theoretically debatable issues or important experimental difficulties [7,8]. This is

\footnotetext{
* Corresponding author at: Seco Tools AB, R\&D Material and Technology Development, Fagersta 73782, Sweden.

E-mail address: saad.sheikh@chalmers.se (S. Sheikh).
}

specifically true for approaches based on conventional fracture mechanics testing, where introduction of sharp and residual stress - free cracks into specimens is required.

Within the above framework, an effort is here proposed to evaluate different fracture toughness testing methodologies where above experimental limitations are avoided: three-point bending on Chevron notched specimen (e.g. Ref. [9]) as "reference" baseline, the practical Palmqvist indentation test, and Hertzian indentation method [10]. In this regard, it is interesting to note that the use of Hertzian indentation method for assessing fracture toughness of cemented carbides has been quite limited [11], even though it offers similar advantages to those commonly ascribed to Palmqvist method, i.e. a straightforward experimental procedure, minimal specimen preparation, and need of small amount of material [10]. The systematic study attempted is conducted in several cemented carbide grades with different microstructures, in terms of both WC grain size and Co binder content. Aiming to have a comprehensive view of fracture toughness-microstructure relationship, the mechanical study is complemented by an accurate estimation of single- and two-phase microstructural parameters, i.e. carbide grain size and cobalt content, as well as cobalt binder mean free path and carbide contiguity, respectively. Finally, experimental findings are analyzed and discussed on the basis of two theoretical models proposed in the literature by other authors. 


\section{Materials and experimental methods}

\section{Materials and microstructural characterization}

Nine different cemented carbides with varying grain size and cobalt content were manufactured for the experiments. The materials were consolidated by liquid phase sintering at temperatures in the range between $1390{ }^{\circ} \mathrm{C}$ and $1470{ }^{\circ} \mathrm{C}$ following the conventional powder metallurgy route. Nominal compositional details with varying cobalt binder content and carbide grain size for each hardmetal grade studied are listed in Table 1. Scanning electron microscopy (SEM) micrographs for four of the investigated materials are shown in Fig. 1.

Microstructure of WC-Co cemented carbides is usually characterized in terms of both single-phase parameters: carbide phase size (d) and cobalt volume fraction $\left(\mathrm{V}_{\mathrm{Co}_{\mathrm{O}}}\right)$, as well as two-phase ones: carbide contiguity (C) and binder mean free path $(\lambda)$. These parameters have great influence on the overall properties of hardmetals. Carbide grain size and contiguity were determined by SEM and electron back scattered diffraction (EBSD) with an EBSD system manufactured by HKL using their Channel 5 software. To obtain high quality patterns for the EBSD analysis the specimens were mechanically polished with diamond slurry to $1 \mu \mathrm{m}$, followed by ion beam etching $\left(\mathrm{Ar}^{+}\right)$in a JEOL cross section polisher (SM-09010) with $6 \mathrm{kV}$ energy and approximately $1^{\circ}$ incident angle. EBSD mapping was performed on a Zeiss Supra 40 high resolution SEM. Optimum step size was chosen in the range $0.06-0.15 \mu \mathrm{m}$ depending on the carbide grain size. The specimens were tilted $70^{\circ}$ using a $20 \mathrm{kV}$ voltage at high current mode with $60 \mu \mathrm{m}$ aperture. After refining the data from faulty indexing, by means of wild spike correction and noise reduction, grain size maps were constructed. Once the refined maps are obtained, the area of each WC grain can be calculated. Carbide grains may be approximated as spherical, as recommended by Stjernberg [12]; and thus, equivalent circle diameter can be used to describe the two dimensional WC grain size. The equivalent diameter for each individual detected grain can then be used for microstructural analysis. Further details on the EBSD characterization are described elsewhere [13-15].

After obtaining orientation maps MATLAB ${ }^{\mathrm{TM}}$ toolbox MTEX, which features a distinctive method for the evaluation of an orientation density function from diffraction pole figure intensities or from EBSD data normally classified by phase, was utilized to determine the number of carbide/carbide $\left(N_{c c}\right)$ and binder/carbide boundaries $\left(N_{b c}\right)$ per unit length. Volume fraction of binder was also calculated using EBSD. On the basis of experimental data gathered, contiguity $(C)$ and binder mean free path $(\lambda)$ were determined according to $[16,17]$ :

$C=\frac{2 N_{C C}}{\left(2 N_{c c}+N_{b c} * \sqrt{(\text { Vol. \% of binder theoretical / Vol. \% obtained from EBSD }))}\right.}$

and

$\lambda=d * \frac{V_{C_{0}}}{\left(1-V_{C_{0}}\right)(1-C)}$.
Microstructural data for the nine hardmetal grades investigated are included in Table 1.

\section{Fracture toughness}

\section{Chevron-notched three-point bending test}

Advantages of toughness measurement of cemented carbides through three-point bending test of Chevron-notched specimens include no pre-cracking requirement and easy testing configuration. Within this context, values assessed following this testing procedure will be used, for comparison purposes, as "reference" baseline for further discussion on testing method and microstructural effects on fracture toughness. Rectangular bars of dimensions $\left(53 \times 3 \times 4 \mathrm{~mm}^{3}\right)$, nine for each hardmetal grade, were manufactured. A Chevron notch was introduced in each specimen by means of electrical discharge machining. Thickness of the cutting wire was $0.15 \mathrm{~mm}$. The Chevron notch angle $(\theta)$ was $90^{\circ}$ while the tip of the notch was positioned at about $1 \mathrm{~mm}$ below the tensile surface. Specimens were broken under three-point bending, with a specimen span $S$ of $16 \mathrm{~mm}$. Tests were conducted in an Instron 8862 electro-mechanical testing device, with overall load capacity of $100 \mathrm{kN}$. For measurement purposes, the device was instrumented with a $5 \mathrm{kN}$ load cell. To be able to measure deflection of the testing sample, a linear variable differential transformer (LVDT) displacement gauge was used during the test. The stress intensity factor for a Chevron notched specimen loaded in flexure under three-point bending can be expressed as [18-20]:

$K_{I c}=\frac{F_{\max } Y_{\min }^{*}}{B(W)^{1 / 2}}$

where $K_{I c}$ is expressed as MPa $\mathrm{m}^{1 / 2}, F_{\max }$ is the maximum load and $Y_{\min }^{*}$ is a geometry factor dependent on $a / W$ [21], where $a$ is initial crack length and $W(4 \mathrm{~mm})$ is the height. Finally, $B(3 \mathrm{~mm})$ is the specimen width.

\section{Palmqvist indentation toughness}

Palmqvist indentation toughness was determined on square shaped $\left(12 \times 12 \times 5 \mathrm{~mm}^{3}\right)$ cemented carbide specimens. Ten indentations for each grade were carried out on diamond polished surfaces. A $0.75 \mathrm{~mm}$ distance between indentations was kept in order to avoid any overlapping effects. Indentation load $(P)$ was $30 \mathrm{kgf}$, as recommended by ISO 3878 and lengths $(L)$ of cracks starting at the corners of indentation were measured by light optical microscopy at 500× magnification. Palmqvist fracture toughness was assessed from Shetty et al.'s equation [22], according to:

$$
K_{I C}=A \sqrt{H}\left(\frac{P}{\Sigma L}\right)
$$

where $H$ is the hardness $\left(\mathrm{N} / \mathrm{mm}^{2}\right), P$ is the applied load $(N), \Sigma L$ is the sum of crack lengths ( $\mathrm{mm}), A$ is a constant with value of 0.0028 , and

Table 1

Composition, microstructural parameters and mechanical properties for all the cemented carbide grades studied.

\begin{tabular}{|c|c|c|c|c|c|c|c|c|c|c|c|}
\hline Grade & Nwc/wc & $\mathrm{Nwc} / \mathrm{co}$ & $\begin{array}{l}\text { vol. } \%-\text { Co } \\
\text { EBSD }\end{array}$ & $\begin{array}{l}\text { vol.\% - Co } \\
\text { (Theor.) }\end{array}$ & $\begin{array}{l}\text { Contiguity } \\
\text { (C) }\end{array}$ & $\begin{array}{c}d \\
(\mu \mathrm{m})\end{array}$ & $\underset{(\mu \mathrm{m})}{\lambda}$ & $\begin{array}{l}\text { Hardness } \\
\text { (HV30) }\end{array}$ & $\mathrm{E}(\mathrm{GPa})$ & $v$ & $\begin{array}{l}\text { TRS } \\
(\mathrm{MPa})\end{array}$ \\
\hline A & 101,001 & 23,898 & 4.2 & 11 & 0.84 & 0.70 & 0.54 & 1782 & 678 & 0.22 & 3130 \\
\hline B & 89,787 & 42,043 & 10.0 & 17 & 0.77 & 0.67 & 0.59 & 1591 & 619 & 0.22 & 3655 \\
\hline C & 76,237 & 55,491 & 15.6 & 21 & 0.70 & 0.67 & 0.60 & 1483 & 599 & 0.22 & 3833 \\
\hline D & 106,697 & 35,855 & 7.5 & 12 & 0.82 & 0.79 & 0.61 & 1748 & 690 & 0.21 & 2129 \\
\hline$E$ & 46,602 & 54,202 & 18.8 & 20 & 0.62 & 0.97 & 0.65 & 1359 & 600 & 0.23 & 2858 \\
\hline $\mathrm{F}$ & 67,551 & 47,822 & 11.9 & 14 & 0.72 & 1.50 & 0.88 & 1426 & 649 & 0.23 & 2486 \\
\hline G & 64,137 & 63,832 & 16.6 & 17 & 0.67 & 1.35 & 0.83 & 1335 & 625 & 0.23 & 2885 \\
\hline $\mathrm{H}$ & 62,623 & 80,272 & 22.3 & 21 & 0.62 & 1.70 & 1.18 & 1264 & 579 & 0.22 & 2904 \\
\hline I & 74,388 & 46,303 & 9.1 & 13 & 0.73 & 2.21 & 1.22 & 1395 & 600 & 0.21 & 2416 \\
\hline
\end{tabular}


a

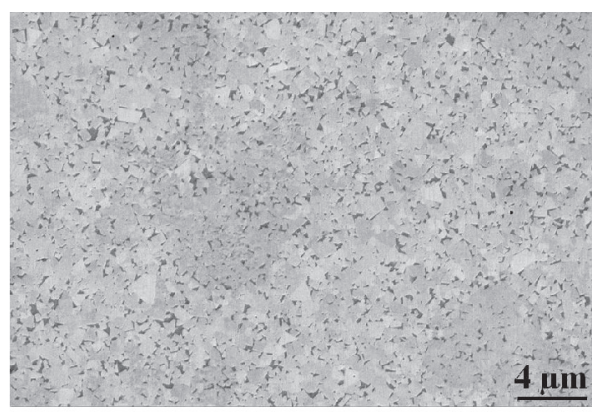

C

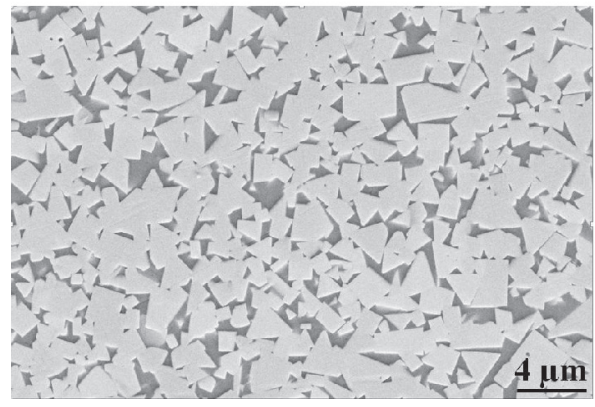

b

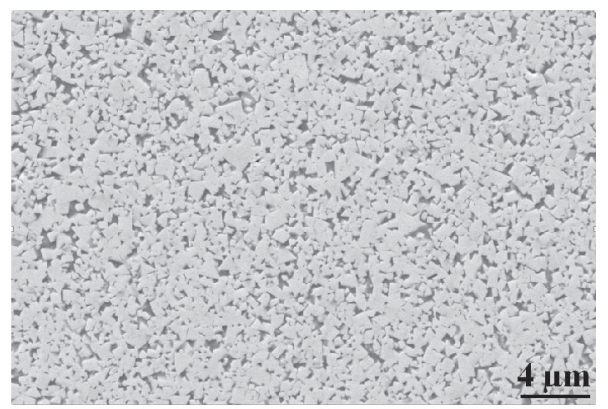

d

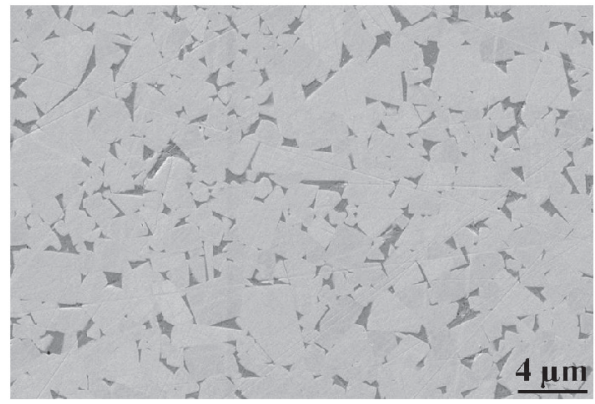

Fig. 1. SEM images of several cemented carbides studied: (a) A, (b) C, (c) H and (d) I.

$K_{I c}$ is given as MPa $\mathrm{m}^{1 / 2}$. For $H V 30$ values expressed in $\left(\mathrm{kgf} / \mathrm{mm}^{2}\right)$, Palmqvist fracture toughness can be calculated as:

$K_{I c}=0.15\left(\frac{H V_{30}}{\Sigma L}\right)$.

\section{Hertzian indentation toughness}

Many attempts have been made to use Hertzian indentation - where a hard sphere is pressed into the flat surface of a brittle substrate - to determine fracture toughness of brittle materials [23-25]. In this study, early experimental limitations on the use of this technique are overcome by following the protocol proposed by Warren [10] which simply requires measurement of the fracture load. It is based on a refined stress intensity factor formulation for surface-breaking cracks in steep-stress gradients [26] which enables estimation of the minimum loads necessary to propagate cracks by Hertzian indentation. Thus, indentation tests on a flat surface of a brittle material, performed with a sphere of given radius $R$ and made of the same material, allow measurement of a definite minimum load of fracture $\left(P_{F \text { min }}\right)$, which is used for determining fracture toughness $\left(K_{I C}\right)$ according to:

$K_{I C}=\left(\frac{E * P_{F \min }}{P_{F N}^{\min } R}\right)^{1 / 2}$

where $E^{*}$ is the reduced "specimen + indenter" Young modulus, and $P_{F N}^{\min }$ is a normalized fracture load necessary to propagate short plane cracks of length $c$, located normal to the free surface and close to the contact zone of radius $a$.

At this stage, it should be emphasized that $P_{F N}^{\min }$ is a dimensionless quantity, exclusively dependent on the Poisson ratio $(v)$ of the material tested $\left(P_{F N}^{\min }\right.$ values for $v$ range relevant for this study are: 2025, 2247 and 2490 for $v$ values of $0.21,0.22$ and 0.23 respectively). On the other hand, occurrence of such fracture (radial cracking) event requires propagation of pre-existing flaws. As a consequence, minimum normalized lengths $(c / a)_{\min }$ corresponding to surface crack depths in the 5$10 \mu \mathrm{m}$ range are required. It points out abrasion with fine $\mathrm{SiC}$ grits, instead of fine diamond polish, as recommended surface preparation method. However, such abrasion may introduce surface residual stresses, and this effect should be analysed too. Accordingly, two different surface conditions were investigated: one attained through abrasion using SiC 600 grit size, and another corresponding to final polishing using 6 micron diamond. After grinding and polishing, residual stress measurements were carried out using X-ray diffraction analysis [27]. Residual stresses were determined in the WC phase in both parallel and transversal directions.

Regarding experimental issues, Hertzian indentation tests were conducted using spherical hardmetal indenters with two different radii i.e. $1.25 \mathrm{~mm}$ and $2.5 \mathrm{~mm}$. After indentation, specimens were inspected with light optical microscope to discern cracking features at the imprint contour. Once the minimum load for cracking was assessed, fracture toughness was finally calculated using Eq. (6). Such a procedure was conducted for each surface condition and indenter radius in four selected hardmetal grades: A, C, H and I.

\section{Results and discussion}

Microstructural parameters obtained from EBSD and relation to basic mechanical properties

Mechanical properties of WC-Co composites are dependent on volume fraction of each phase and carbide grain size. As the volume fraction of the carbide phase increases, hardness rises and fracture toughness decreases. On the other hand, grades with fine carbides exhibit higher hardness and lower fracture toughness than those with a coarser microstructure. The combined effect of these single-phase parameters may be captured by means of two-phase microstructural parameters such as carbide contiguity and binder mean free path. In general, contiguity is observed to increase as both binder content and carbide grain size decrease. Fig. 2 shows EBSD maps obtained. In such images, red and green boundaries correspond to WC-Co and WC-WC interfaces respectively. 


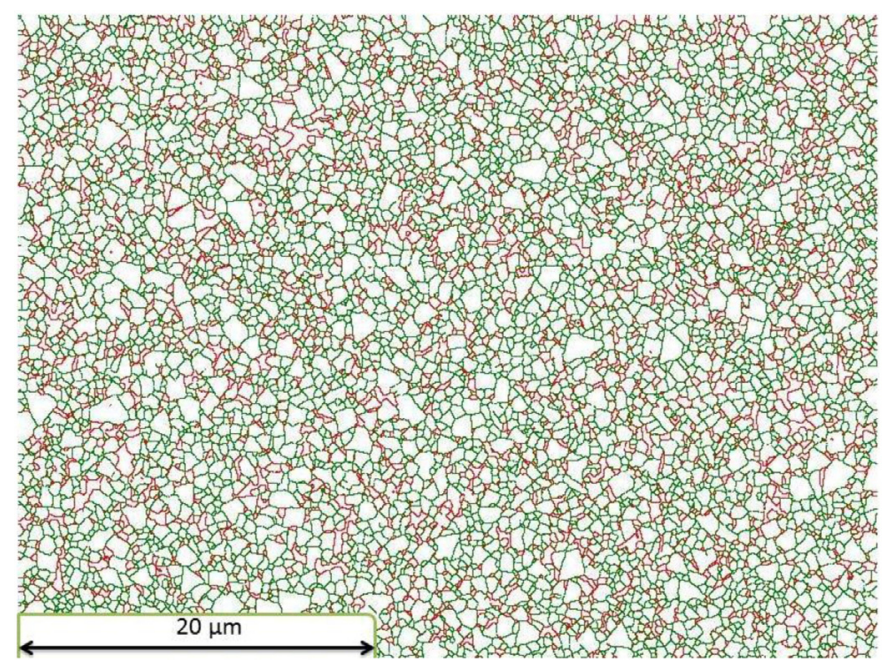

Fig. 2. EBSD map after noise reduction for grade A. WC-Co and WC-WC interfaces are represented by red and green colors respectively. (For interpretation of the references to color in this figure legend, the reader is referred to the web version of this article.)

Microstructural characteristics, including volume fraction of binder phase, determined from EBSD measurements are presented in Table 1. Values for basic mechanical properties: elastic modulus (E) and Poisson's ratio (v), determined according to ASTM E1876-01, and hardness (HV30) are also listed in Table 1. As expected, hardness is discerned to decrease as binder mean free path rises (Fig. 3).

\section{Fracture toughness-microstructure correlation}

Chevron-notched three-point bending test is an efficient method for fracture toughness assessment of brittle cemented carbides. In this study, deflection was recorded by a LVDT device and a typical forcedeflection curve is shown in Fig. 4. At a critical crack length, the load required to propagate the crack passes through a maximum, and such value is then used for determining fracture toughness. Main advantage of this method is that it avoids any precracking requirement. The values obtained by using this testing method are here used as baseline and are thus referred as "reference" $K_{I c}$. Figs. 5-7 display the variation of "reference" $K_{I c}$ as a function of hardness, carbide contiguity and binder mean free path, respectively. The results indicate a consistent decrease of fracture toughness with increasing hardness and carbide contiguity. An increase of toughness with rising binder mean free path is also discerned, although changes are less pronounced for $\lambda$ values above 0.70 , in agreement with results from the literature (e.g. [28]).

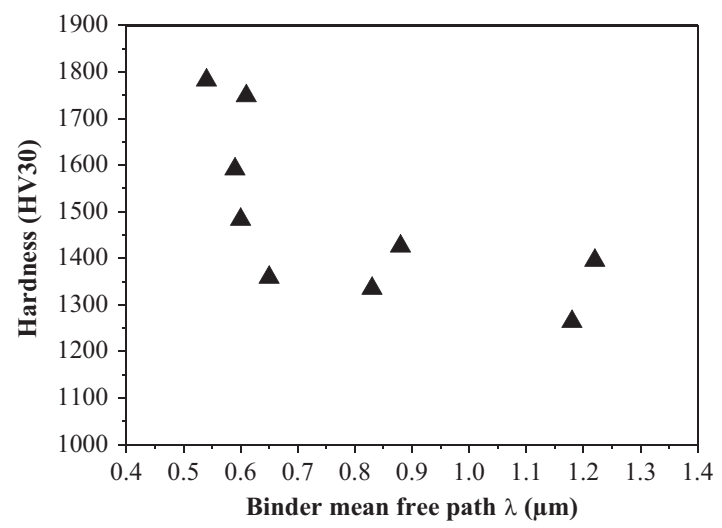

Fig. 3. Hardness as a function of binder mean free path for hardmetal grades studied.

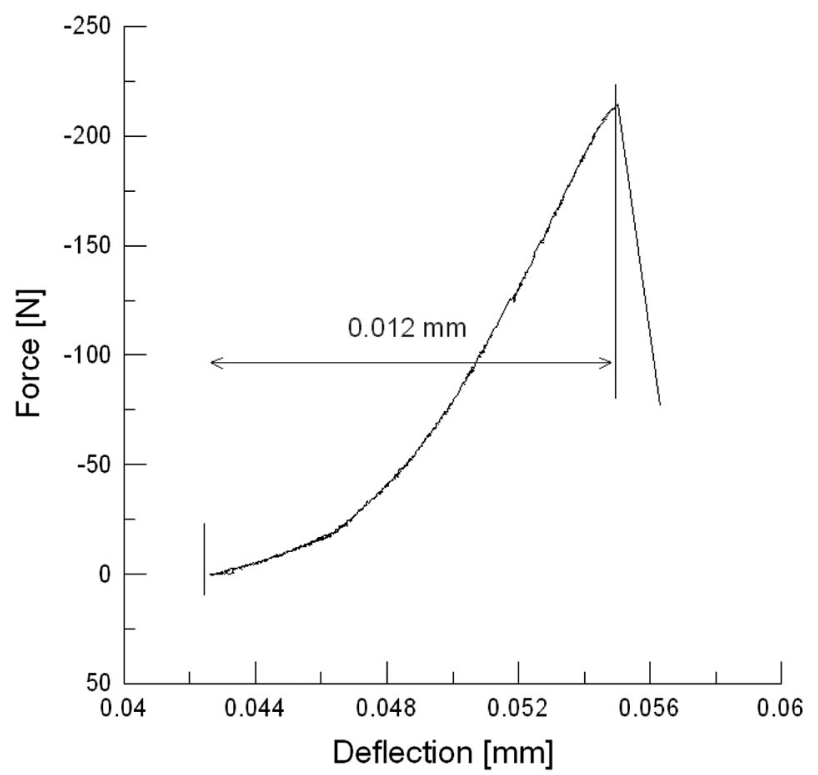

Fig. 4. Typical curve representing force vs. deflection response recorded during fracture toughness testing of a Chevron-notched specimen (grade B).

Influence of testing method on fracture toughness measurement

A comparison of the fracture toughness values obtained by the different testing methods investigated is shown in Table 2. For most of the hardmetal grades studied, a reasonably good agreement is found between $K_{I c}$ values obtained through Chevron-notched three-point bending test and Palmqvist indentation. It corresponds to a toughness range from 10 to $14 \mathrm{MPa} \mathrm{m}^{1 / 2}$. However, this was not the case for grade $\mathrm{H}$ which exhibits a relatively higher toughness level.

Depending on indenter shape, three distinct indentation modes take place in brittle materials. Ring cracks and Hertzian cone cracks are formed when indenter is rounded while lateral vents or median vents are formed when the indenter is sharp. For the case of cemented carbides, median vents are formed in the underlying material and they may be classified in two types: Palmqvist and median cracks. Schematic of this indentation-induced crack system is described in detail elsewhere [29]. Crack geometry beneath indentation for grade A is shown in Fig. 8. This was the cracking scenario discerned for most of the hardmetal grades studied. It clearly follows a Palmqvist crack geometry, a necessary condition for assessing fracture toughness through Eq. (4).

On the other hand, the combined effect of high binder content and relatively coarse carbides (e.g. H grade) results in a relevant departure

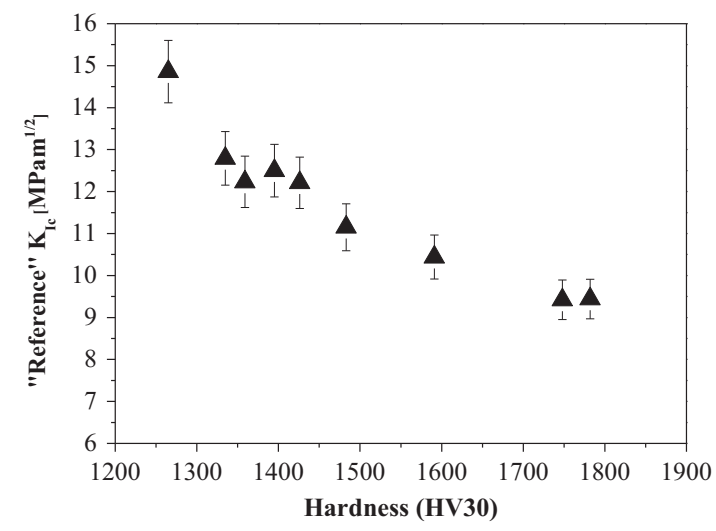

Fig. 5. "Reference" fracture toughness (measured by means of Chevron-notched threepoint bending test) vs. hardness for hardmetal grades investigated. 


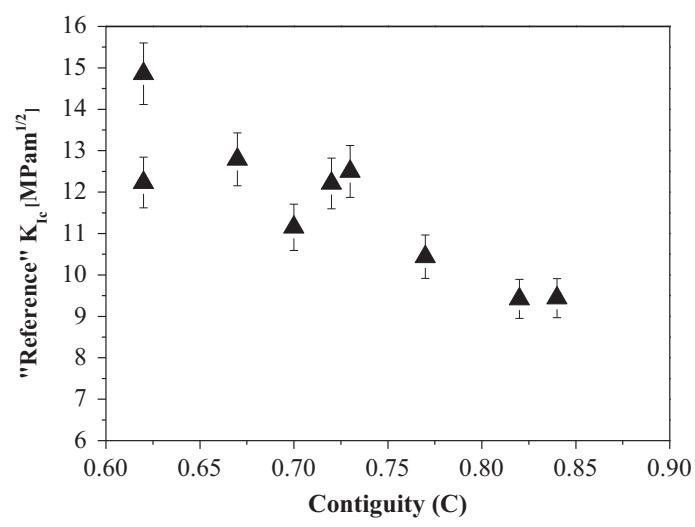

Fig. 6. "Reference" fracture toughness (measured by means of Chevron-notched threepoint bending test) as a function of carbide contiguity for hardmetal grades studied.

from the brittle-like nature suitable for satisfying requirements implicit to application of indentation fracture mechanics [5,7]. For cemented carbide $\mathrm{H}$, a well-defined cracking system (with long enough fissures, as compared to indentation impression size) is not developed at the corners of Vicker's indentations, even if applied load is risen up to $100 \mathrm{kgf}$. Moreover, increasing the load above $30 \mathrm{kgf}$ also implies a damage or failure risk for the indenter. Fig. 9 shows indentation imprints and induced cracks (under the same indentation load) for materials $\mathrm{C}$ and $\mathrm{H}$, grades with similar cobalt binder content but different carbide grain size. Looking at the cracking system generated in the $\mathrm{H}$ grade, it is evident that some of the hypothesis assumed in developing relationships like Shetty et al.'s equation, based on an approximate fracture mechanics analysis [22], are not valid for relatively tough (above $14 \mathrm{MPa} \mathrm{m}^{1 / 2}$ ) hardmetals. As a consequence, toughness assessed from Shetty et al.'s equation in those materials yield overestimated values.

Regarding toughness assessment by means of Hertzian indentation (using an indenter of radius $1.25 \mathrm{~mm}$ and surface finish resulting from final polishing using 6 micron diamond), it seems to yield overestimated values for the two fine-grained grades tested (i.e. A and D materials). On the other hand, it results in quite concordant values, as compared to those measured by means of the reference Chevron-notched three-point bending test, for the medium/coarse grained grades (i.e. $\mathrm{H}$ and I).

Aiming for a deeper study on the implementation of Hertzian indentation methodology, the use of indenters with different radii and surface conditions (abraded with SiC 600 grit size and polished with 6 micron diamond) was tested. Ring cracks formed at the surface of grade $C$, at applied critical load using the $2.5 \mathrm{~mm}$ radius indenter, for the two referred surface conditions are shown in Fig. 10. Furthermore, as surface residual stresses were expected to be introduced through abrasion with SiC 600

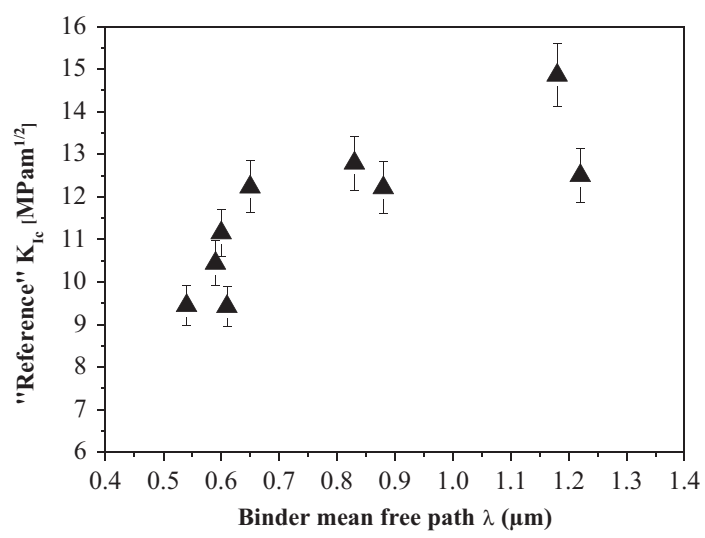

Fig. 7. "Reference" fracture toughness (measured by means of Chevron-notched three-point bending test) as a function of binder mean free path for hardmetal grades investigated.
Table 2

Fracture toughness values determined using different testing methods: "reference" Chevron-notched three-point bending, Palmqvist indentation and Hertzian indentation (1.25 $\mathrm{mm}$ indenter radius and surface condition corresponding to 6 micron diamond polished).

\begin{tabular}{llcl}
\hline Grade & $\begin{array}{l}\text { Chevron-notched } \\
\text { three-point bending } \\
\text { "reference } \mathrm{K}_{\mathrm{lc}} \text { " } \\
\left(\mathrm{MPa} \mathrm{m}^{1 / 2}\right)\end{array}$ & $\begin{array}{l}\text { Palmqvist indentation } \\
\text { toughness }\left(\mathrm{MPa} \mathrm{m}^{1 / 2}\right)\end{array}$ & $\begin{array}{l}\text { Hertzian indentation } \\
\text { toughness }\left(\mathrm{MPa} \mathrm{m}^{1 / 2}\right)\end{array}$ \\
\hline $\mathrm{A}$ & 9.4 & 9.4 & 11.7 \\
$\mathrm{~B}$ & 10.4 & 11.0 & \\
$\mathrm{C}$ & 11.2 & 12.3 & 14.5 \\
$\mathrm{D}$ & 9.4 & 9.2 & \\
$\mathrm{E}$ & 12.2 & 13.6 & \\
$\mathrm{~F}$ & 12.2 & 11.8 & \\
$\mathrm{G}$ & 12.8 & 13.8 & 15.1 \\
$\mathrm{H}$ & 14.9 & 20.8 & 12.1 \\
$\mathrm{I}$ & 12.5 & 12.0 & \\
\hline
\end{tabular}

grit size, they were measured on two different surfaces, parallel and transverse directions [27]. The results obtained are shown in Table 3. It is evident that compressive residual stresses are much higher for abraded specimens than for polished ones. However, and very interesting, they are higher for the harder grades. The effect of different surface treatments (and residual stresses) along with varying spherical indenter radii $\left(r_{e}\right)$ on fracture toughness is shown in Table 4. The higher toughness values determined for abraded specimens, as compared to the polished ones under similar testing conditions, are intimately related to the compressive residual stresses induced during surface preparation in the former.

In order to obtain the appropriate toughness values through Hertzian indentation using spheres with radii between 1 and $5 \mathrm{~mm}$, preexisting flaws of length between 5 and $10 \mu \mathrm{m}$ are required. Accordingly, a relatively coarse surface texture is needed. However, mechanical treatment of surfaces for attaining such rough-like profile usually results in relevant surface residual stresses (e.g. Table 3); which may then result in overestimated fracture toughness values. Even if residual stresses are disregarded, an intrinsic overestimation should also be expected, as the flaw density is not infinite in reality, and cracks will not be situated at the particular position for which critical stress intensity factor is minimum. Beyond these experimental limitations, the main advantage of using this method should also be emphasized: it does not require any measurement of radius of ring-crack and there is no need to determine initial crack size.

Following the above findings, from a practical view it is finally interesting to evaluate the particular measurement suitability of each method as a function of a basic mechanical property such as hardness. In this

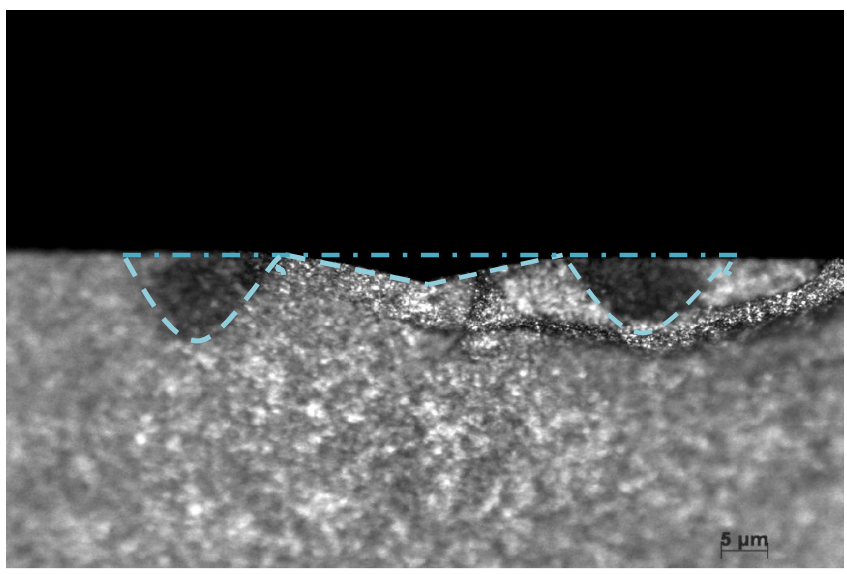

Fig. 8. Palmqvist crack geometry beneath indentation for hardmetal grade A with Palmqvist profile outlined with dotted lines. 
a

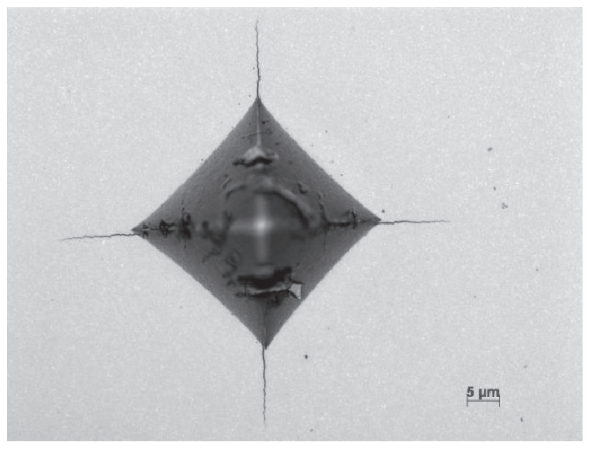

b

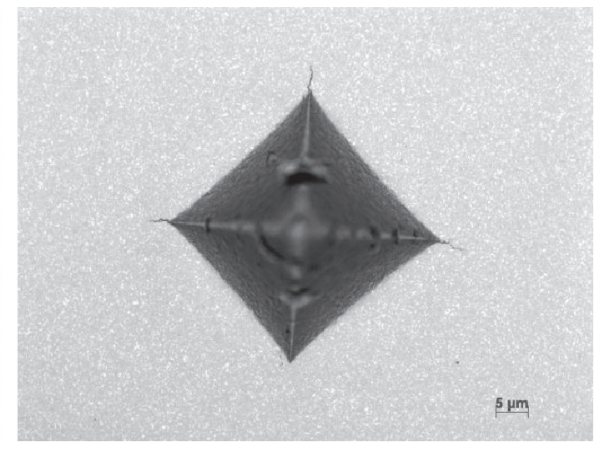

Fig. 9. Micrographs of Vickers' indentations and induced surface radial cracking in hardmetal grades $\mathrm{C}$ and $\mathrm{H}$.

$\mathbf{a}$

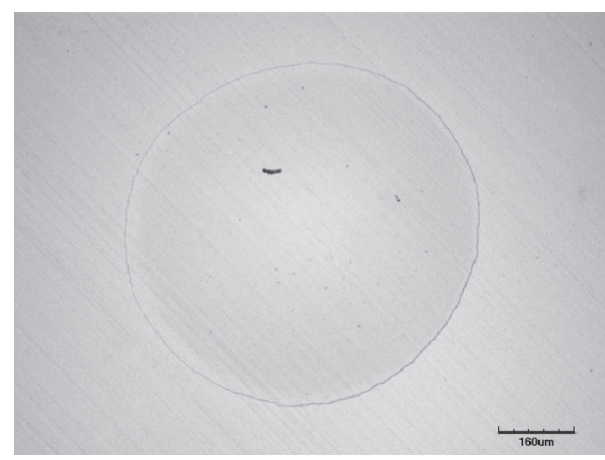

b

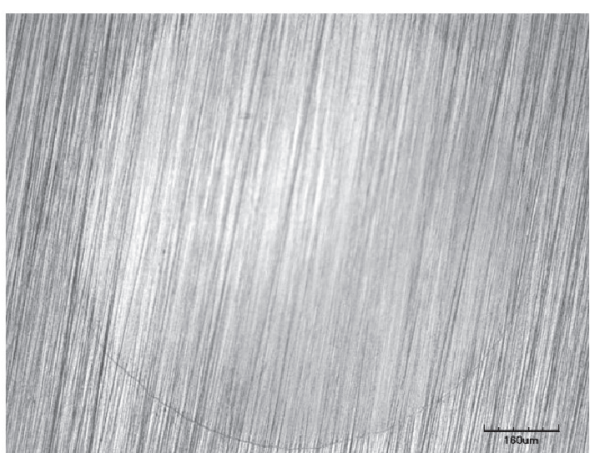

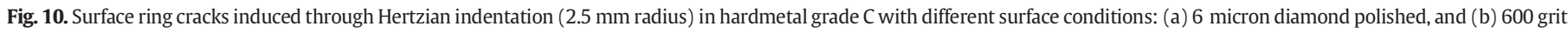
size SiC abraded.

regard, Chevron-notched three-point bending test yields suitable fracture toughness values for a wide range of cemented carbide grades with varying hardness. Concerning indentation methods, the Hertzian one may be particularly recommended, as compared to Palmqvist method, as far as hardness (HV30) drops below 1300. On the other hand, if HV is higher than 1300; results estimated from Shetty et al.'s equation may be taken as suitable for assessment of fracture toughness.

\section{Theoretical considerations}

Based on different microstructural parameters and assuming deformation in cobalt binder and carbides, different fracture toughness models have been proposed in the literature. Using these microstructural parameters, an effort is here carried out to evaluate how experimental data gathered in this study fit within estimations extracted from two specific models.

Table 3

Surface residual stresses associated with different surface conditions (6 micron diamond polished and 600 grit size SiC abraded) for all hardmetal grades A, C, H and I.

\begin{tabular}{llll}
\hline Grade & $\begin{array}{l}\text { Residual stresses } \\
\text { (parallel direction) }\end{array}$ & $\begin{array}{l}\text { Residual stresses } \\
\text { (transverse direction) }\end{array}$ & $\begin{array}{l}\text { Surface } \\
\text { condition }\end{array}$ \\
\hline A & $-305 \pm 37$ & $-253 \pm 23$ & Polished \\
C & $-325 \pm 38$ & $-395 \pm 36$ & Polished \\
H & $-435 \pm 32$ & $-399 \pm 28$ & Polished \\
I & $-311 \pm 38$ & $-332 \pm 24$ & Polished \\
A & $-3384 \pm 104$ & $-2966 \pm 64$ & Abraded \\
C & $-2577 \pm 87$ & $-2569 \pm 103$ & Abraded \\
H & $-1985 \pm 49$ & $-1984 \pm 76$ & Abraded \\
I & $-2014 \pm 44$ & $-2132 \pm 79$ & Abraded \\
\hline
\end{tabular}

Godse and Gurland's model (GGM) [30]

This model uses the idea of ductile fracture proposed by Rice and Johnson [31], i.e. a critical strain should be exceeded for crack growth to take place. Fracture toughness obtained using this model is based on the fact that crack growth resistance mainly comes from reinforcement provided by the ductile binder (cobalt) acting as ligaments along the crack wake, and is valid for $10 \%$ to $25 \%$ binder volume fraction.

Fracture toughness $K_{I c}$ may be estimated from Eq. (9):

$K_{I C}=\sqrt{R(\lambda+d) E^{\prime} \sigma_{B} \frac{\left(1-C V_{W C}\right)}{C_{1}}}$

Table 4

Fracture toughness measured through Hertzian indentation (indenter elastic properties: $\mathrm{E}^{\prime}=700 \mathrm{GPa}$ and $v^{\prime}=0.2$ ) for hardmetal grades $\mathrm{A}, \mathrm{C}, \mathrm{H}$ and I; using different indenter radius and surface conditions.

\begin{tabular}{lllllll}
\hline Grade & $\begin{array}{l}\text { Surface } \\
\text { condition }\end{array}$ & $\begin{array}{c}E^{*} \\
(\mathrm{GPa})\end{array}$ & $\begin{array}{l}P_{f \min } \\
(\mathrm{N})\end{array}$ & $P_{F N}^{\min }$ & $\begin{array}{c}r_{e} \\
(\mathrm{~mm})\end{array}$ & $\begin{array}{l}K_{I c} \\
\left(\mathrm{MPa} \mathrm{m}^{1 / 2}\right)\end{array}$ \\
\hline A & Polished & 360 & 3816 & 2247 & 2.50 & 15.7 \\
C & Polished & 338 & 4186 & 2247 & 2.50 & 15.9 \\
H & Polished & 332 & 5037 & 2247 & 2.50 & 17.2 \\
I & Polished & 337 & 3263 & 2025 & 2.50 & 14.8 \\
A & Polished & 360 & 1073 & 2247 & 1.25 & 11.7 \\
C & Polished & 338 & 1754 & 2247 & 1.25 & 14.5 \\
H & Polished & 332 & 1954 & 2247 & 1.25 & 15.1 \\
I & Polished & 337 & 1103 & 2025 & 1.25 & 12.1 \\
A & Abraded & 360 & 4806 & 2247 & 2.50 & 17.5 \\
C & Abraded & 338 & 8567 & 2247 & 2.50 & 22.7 \\
H & Abraded & 332 & 8817 & 2247 & 2.50 & 22.9 \\
I & Abraded & 337 & 4946 & 2025 & 2.50 & 18.1 \\
\hline
\end{tabular}


where $C, d$ and $V_{W C}$ are the contiguity, grain size and volume fraction of the carbide phase respectively; $\lambda$ is the binder mean free path; $R$ is a floating parameter calculated on the basis of best fitting with experimental data [30], $C_{1}$ is taken from McMeeking's work [32] as $0.54, E^{\prime}$ can be calculated by using Eq. (10) for plane stress:

$E^{\prime}=\frac{E}{1-U^{2}}$

and $\sigma_{B}$ is the binder effective flow stress, calculated by using Eq. (11) as proposed by Sigl and Fischmeister [6]:

$\sigma_{B}=480+\frac{1550}{\lambda}[\mathrm{MPa}]$.

\section{Ravichandran's model (RM) [33]}

Ravichandran proposed evaluation of the strain energy release rate $\left(G_{c}\right)$ as the sum of fracture resistance of binder phase and fracture energy of carbide phase [33] according to Eq. (12):

$G_{C}=\left(1-V_{f}\right) G_{m}+V_{f} \sigma_{0} h \lambda$

where $G_{m}$ is the strain energy release rate of the brittle WC phase, $\lambda$ is the binder mean free path, and $V_{f}$ and $\sigma_{o}$ are volume fraction and bulk flow stress of binder. $\chi$ is defined as the work of rupture, a parameter related to bulk flow stress of the binder as follows:

$\chi=\sigma_{e f f} \frac{\beta}{\sigma_{O}}$

where $\sigma_{\text {eff }}$ is the effective flow stress, and may be estimated from:

$\frac{\sigma_{e f f}}{\sigma_{0}}=\left[1+\frac{2 k}{3}\left(\frac{d}{2 \lambda}\right)\right]$

where $d$ is the carbide grain size and $k$ is the maximum shear factor (with a value of 0.577 ).

As a final outcome, fracture toughness can be determined by the following relation (15):

$K_{I c}=\sqrt{\frac{E_{C}\left(1-v_{m}^{2}\right)\left(1-V_{f}\right) K_{m}^{2}}{\left(1-v_{C}^{2}\right) E_{m}}+\frac{\beta V_{f} E_{C} \sigma_{e f f} \lambda}{\left(1-v_{C}^{2}\right)}}$

where $K_{I c}$ is the fracture toughness of the hardmetal under consideration, $E_{C}$ and $v_{C}$ are elastic modulus and Poisson's ratio of the WC-Co composite, $\beta$ is defined as the ratio of critical crack tip to binder thickness and is taken to be 2 by Ravichadran; and $K_{m}, E_{m}$ and $v_{m}$ are fracture toughness, elastic modulus and Poisson's ratio of the brittle WC (matrix) phase.

Fitting of experimental data to the models under consideration

A comparison between the "reference" $K_{I C}$ values and estimations resulting from the above theoretical models are presented in Table 5. Both theoretical models utilize different binder flow stress and this is something that needs to be further explored. For instance, RM considers a binder flow stress of $850 \mathrm{MPa}$, which is lower than the binder flow stress proposed in GGM. Implementation of GGM model seems to overestimate the experimental values attained in this study. This is also the case for RM model wherein a value of 2 is taken for $\beta$. However, a slight modification of this parameter $(\beta=1.1)$, indicative of an almost oneto-one relationship between critical crack tip opening displacement at fracture and binder thickness yields a satisfactory fitting of the experimental data. Further exploitation and adjustment may be done in order to have better estimations from these models.
Table 5

Estimated fracture toughness on the basis of RM and GGM theoretical models.

\begin{tabular}{|c|c|c|c|}
\hline \multirow[t]{3}{*}{ Grade } & $\mathrm{RM}(\beta=2)$ & $\mathrm{RM}(\beta=1.1)$ & GGM \\
\hline & $\mathrm{K}_{\mathrm{Ic}}$ & $\mathrm{K}_{\mathrm{Ic}}$ & $\mathrm{K}_{\mathrm{Ic}}$ \\
\hline & $\overline{\left(\mathrm{MPa} \mathrm{m}^{1 / 2}\right)}$ & $\left(\mathrm{MPa} \mathrm{m}^{1 / 2}\right)$ & $\overline{\left(\mathrm{MPa} \mathrm{m} \mathrm{m}^{1 / 2}\right)}$ \\
\hline A & 11.7 & 9.6 & 13.5 \\
\hline B & 14.0 & 11.1 & 16.3 \\
\hline C & 15.3 & 12.0 & 17.9 \\
\hline $\mathrm{D}$ & 12.6 & 10.2 & 14.7 \\
\hline $\mathrm{E}$ & 15.6 & 12.2 & 19.5 \\
\hline $\mathrm{F}$ & 15.3 & 12.1 & 19.4 \\
\hline G & 16.7 & 13.0 & 20.4 \\
\hline $\mathrm{H}$ & 21.1 & 16.1 & 24.4 \\
\hline I & 17.8 & 13.1 & 21.5 \\
\hline
\end{tabular}

\section{Conclusions}

The conclusions obtained in this study can be summarized as follows:

- Chevron-notch three-point bending test may be taken as "reference" baseline method for determining the fracture toughness for a wide range of binder composition and carbide grain size of hardmetals. Palmqvist method gives a good approximation of toughness for brittle-like cemented carbides, but becomes invalid for grades whose "reference" toughness is higher than $14 \mathrm{MPa} \mathrm{m}^{1 / 2}$. Regarding spherical indentation, optimum indenter radius along with flat surface, free from residual stresses, are important for the determination of fracture toughness. Hertzian indentation may result in overestimated values, this discrepancy becoming significant as hardness of the hardmetal increases, i.e. as binder content and/or carbide grain size decreases.

- Current fracture toughness models overestimates the experimental "reference" fracture toughness values determined in this study. Slight modifications on fitting parameters associated with intrinsic uncertainties (binder flow stress, critical crack tip opening displacement at fracture, etc.) result in satisfactory agreement between experimental and estimated values.

\section{Acknowledgment}

The research work was conducted within a cooperative effort among Seco Tools AB, Pramet Tools, Universitat Politècnica de Catalunya and Chalmers University. This investigation has been partly funded by the Spanish Ministerio de Economia y Competitividad (Grant MAT 201234602). One of the authors (J.Y.) acknowledges funding received through Erasmus Mundus joint European Doctoral Programme DocMASE.

\section{References}

[1] L. Prakash, Introduction to hardmetals - fundamentals and general applications of hardmetals, in: D. Mari, L. Llanes, V.K. Sarin (Eds.), Comprehensive Hard Materials, Hardmetals, vol. 1, Elsevier, 2014, pp. 29-90.

[2] H.E. Exner, A. Walter, R. Pabst, Zur ermittlung und darstellung der fehlerverteilungen von spröden werkstoffen, Mater Sci Eng 16 (1974) 231-238.

[3] J.R. Pickens, J. Gurland, The fracture toughness of WC-Co alloys measured on singleedge notched beam specimens precracked by electron discharge machining, Mater Sci Eng 33 (1978) 135-142.

[4] R.K. Viswanadham, T.S. Sun, E.F. Drake, J.A. Peck, Quantitative fractography of WCCo cermets by Auger spectroscopy, J Mater Sci 16 (1981) 1029-1038.

[5] D.K. Shetty, I.G. Wright, P.N. Mincer, A.H. Clauer, Indentation fracture of WC-Co cermets, J Mater Sci 20 (1985) 1873-1882.

[6] L.S. Sigl, H.F. Fischmeister, On the fracture toughness of cemented carbides, Acta Metall 36 (1988) 887-897.

[7] Y. Torres, D. Casellas, M. Anglada, L. Llanes, Fracture toughness evaluation of hardmetals: influence of testing procedure, Int J Refract Met Hard Mater 19 (2001) 27-34

[8] B. Roebuck, M.G. Gee, R. Morrell, Developments in testing and mechanical properties of hard materials, Powder Metall 39 (1996) 213-218 
[9] M. Sakai, R.C. Bradt, Fracture toughness testing of brittle materials, Int Mater Rev 38 (1993) 53-78.

[10] P.D. Warren, Determining the fracture toughness of brittle materials by Hertzian indentation, J Eur Ceram Soc 15 (1995) 201-207.

[11] M.T. Laugier, Hertzian indentation of ultra-fine grain size WC-Co composites, J Mater Sci Lett 6 (1987) 841-843.

[12] K.G. Stjernberg, Determination of Volume Distribution Function by Lineal Analysis, Chalmers University of Technology, Gothenburg, Sweden, 1969.

[13] F.J. Humphreys, Grain and sub grain characterization by electron backscatter diffraction, J Mater Sci 36 (2001) 3833-3854.

[14] V. Randle, Microtexture Determination and Its Applications, 2nd ed. Institute of Materials/Maney, London, 2003.

[15] K.P. Mingard, B. Roebuck, E.G. Bennett, M.G. Gee, H. Nordenstrom, G. Sweetman, et al., Comparison of EBSD and conventional methods of grain size measurement of hardmetals, Int J Refract Met Hard Mater 27 (2009) 213-222.

[16] B. Roebuck, E.G. Bennett, Phase size distribution in WC/Co hardmetal, Metallography 19 (1986) 27-47.

[17] Z.-H. Xu, J. Ågren, A modified hardness model for WC-Co cemented carbides, Mater Sci Eng A386 (2004) 262-268.

[18] L.M. Barker, Theory for determining $K_{\mathrm{I}}$, from small, non-LEFM specimens, supported by experiments on aluminum, Int J Fract 15 (1979) 515-536.

[19] D. Munz, R.T. Bubsey, J.E. Srawley, Compliance and stress intensity coefficient for short bar specimens with chevron notches, Int J Fract 16 (1980) 359-374.

[20] X. Deng, J. Bitler, K.K. Chawla, B.R. Patterson, Toughness measurement of cemented carbides with Chevron-notched three-point bend test, Adv Eng Mater 12 (2010) 948-952.
[21] S.B. Biner, J.T. Barnby, D.W.J. Elwell, On the use of short-rod/bar test specimens to determine the fracture toughness of metallic materials, Int J Fract 26 (1984) 3-16.

[22] D.K. Shetty, I.G. Wright, P.N. Mincer, A.H. Clauer, Indentation fracture of WC-Co cermets, J Mater Sci 20 (1985) 1873-1882.

[23] F.C. Frank, B.R. Lawn, On the theory of Hertzian fracture, Proc R Soc Lond A229 (1967) 291-306.

[24] T.R. Wilshaw, The Hertzian fracture test, J Phys D Appl Phys 4 (1971) 1567-1581.

[25] A. Franco Jr., S.G. Roberts, Surface mechanical analyses by Hertzian indentation, Cerâmica 50 (2004) 94-108.

[26] P.D. Warren, D.A. Hills, S.G. Roberts, Surface flaw distributions in brittle materials and Hertzian fracture, J Mater Res 9 (1994) 3194-3202.

[27] C. Larsson, M. Odén, X-ray diffraction determination of residual stresses in functionally graded WC-Co composites, Int J Refract Met Hard Mater 22 (2004) 177-184.

[28] L. Llanes, Y. Torres, M. Anglada, On the fatigue crack growth behavior of WC-Co cemented carbides: kinetics description, microstructural effects and fatigue sensitivity, Acta Mater 50 (2002) 2381-2393.

[29] R. Spiegler, S. Schmauder, L.S. Sigl, Fracture toughness evaluation of WC-Co alloys by indentation testing. J Hard Mater 1 (1990) 147-158.

[30] R. Godse, J. Gurland, Applicability of the critical strain fracture criterion to WC-Co hardmetals, Mater Sci Eng A105/106 (1988) 331-336.

[31] J.R. Rice, M.A. Johnson, Inelastic Behavior of Solids, in: M.F. Kanninen, W.F. Adler, A.R Rosenfield, R.I. Jaffe (Eds.), McGraw-Hill, New York, 1970.

[32] R.M. Mcmeeking, Finite deformation analysis of crack-tip opening in elastic-plastic materials and implications for fracture, J Mech Phys Solids 25 (1977) 357-381.

[33] K.S. Ravichandran, Fracture toughness of two phase WC-Co cermets, Acta Metall Mater 42 (1994) 143-150. 